\title{
The Evolution of Disability during the Last Years in Romania and EU Member States
}

\author{
Roxana Elena Mirică1, Ioana Soare ${ }^{2}$ \\ ${ }^{1}$ Faculty of Medicine, "Carol Davila" University of Medicine and Pharmacy, Bucharest, Romania \\ ${ }^{2}$ Faculty of Medicine, “Titu Maiorescu” University, Bucharest, Romania \\ Email:roxmirica@yahoo.com
}

How to cite this paper: Mirică, R.E. and Soare, I. (2020) The Evolution of Disability during the Last Years in Romania and EU Member States. Open Journal of Preventive Medicine, 10, 169-174.

https://doi.org/10.4236/ojpm.2020.107012

Received: June 13, 2020

Accepted: July 19, 2020

Published: July 22, 2020

Copyright $\odot 2020$ by author(s) and Scientific Research Publishing Inc. This work is licensed under the Creative Commons Attribution International License (CC BY 4.0). http://creativecommons.org/licenses/by/4.0/

\begin{abstract}
Purpose: People with disabilities represent a major objective, a global public health issue. This disadvantaged category needs protection and integration into society by implementing an improved legislative framework. The effectiveness of the policy making, consolidating the benefit programs and enhancing equity of the social insurance system represent the key of The Governments strategy. Methods: The paper highlights comparable data and research related to disability and social insurance system from Romania and other Member States of the European Union. Internationally, a proper measurement of disability may lead to a successful removal of barriers which increase the vulnerability of people with disability. Results: According to official data, in Romania the number of disabled people decreased gradually one year to another (in the last 5 years). In the EU Member States, musculoskeletal disorders leading to disability were one of the most common compared to Romania where it ranked last. From the point of view of the share in the total number of people with disabilities, according to the degree of disability, both in the EU Member States and in Romania, the number of moderately disabled people was double, respectively triple compared to the number of those with severe disability. Conclusion: The Romania Government promotes social-professional integration of people with disabilities, being responsible for the guidance, vocational counselling and employment. In accordance with our law, "any person with disabilities, fit and included in the labor market in Romania is entitled to a reasonable accommodation of the workplace."
\end{abstract}

\section{Keywords}

Disability, Degree of Disability, Social Insurance Physicians 


\section{Introduction}

The World Health Organization (WHO) has reported about 15\% of the world's population as having some form of disability [1].

"Disability" is a "continuous" or "considerable" health condition which prioritizes the prevention of impairment, medical treatment and rehabilitation of persons with disabilities [Committee on the Rights of Persons with Disabilities-10 May 2017, CRPD/C/IRN/CO/1, para. 8(a)].

Patients with disabilities undergo a multidisciplinary evaluation, from a medical and psychosocial point of view [2].

\section{Material and Methods}

This is a review of the statistic official information provided by National Institute of Medical Expertise and Work Capacity from Bucharest (Romania) and WHO and it highlights the evolution of disability in Romania compared to the Member States of the European Union in recent years depending on the conditions of the evaluated patients and the degree of disability. People with disabilities are those whose somatic, physical or mental disorders affect their ability to carry out daily activities normally, requiring protection measures in support of social recovery and integration [3].

\section{Discussion and Results}

The aim of this article is underlining official statistics on disabled patients, including new cases (persons to be assessed) and revised cases (with an established disability degree) in Romania, between January 2015 and December 2019, as compared to EU countries.

We have focused on the major four groups of diseases, assessed both by EU member states and by Romania:

1) Somatic ones, which include cardiovascular, respiratory, digestive, kidney, endocrine and diabetes-nutrition related diseases.

2) Musculoskeletal ones (arthritis, degenerative disc diseases).

3) Neurological ones (epilepsy, stroke).

4) Psychiatric ones (depression, personality disorders, mood instability, neuroses, schizophrenia).

The evolution of the number of people with disabilities in Romania in the period 2015-2019 is presented in Figure 1.

In 2016, EU-SILC (European Union Statistics on Income and Living Conditions) reported that $85.7 \%$ of the total severe chronic illnesses have resulted in invalidity [4].

In Romania the most frequent illnesses of the disability compensation beneficiaries are the somatic ones, followed by psychiatric and neurological illnesses, while the musculoskeletal ones are approx. 6 times less frequent. The EU statistics state that the percentages of somatic and musculoskeletal illnesses are almost equal (19.2\% and $18.6 \%$ respectively) (Figure 2 ). 


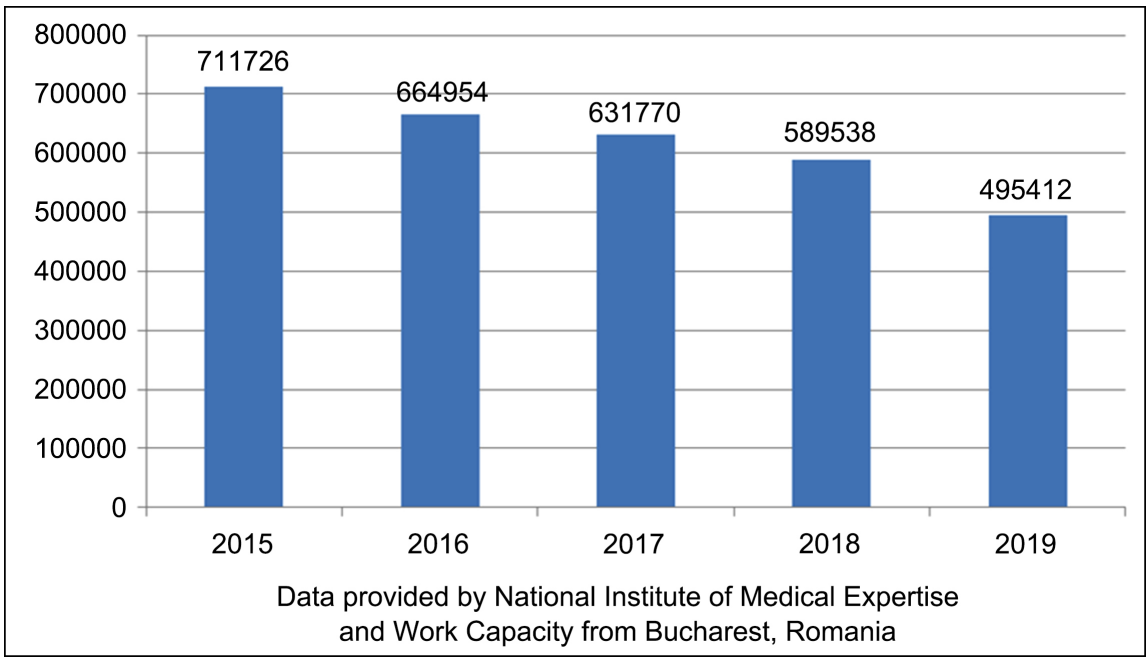

Figure 1. The number of people with disabilities in Romania.

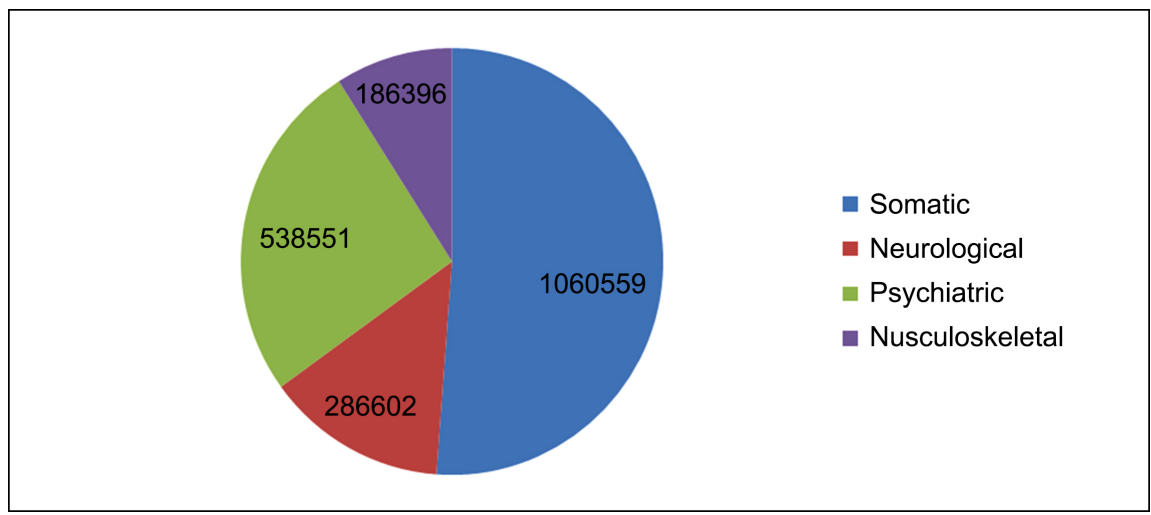

Figure 2. The most frequent chronic illnesses which lead to invalidity in Romania.

The degree of disability plays an important role, expressing the illness severity (Table 1).

In EU Member States, the percentage of patients classified as "moderate disability" (17.3\% in 2015 and $16.6 \%$ in 2016) was double as compared to the one of "severe disability" patients ( $8 \%$ in 2015 and $7.5 \%$ in 2016), while in Romania, within the same period, it tripled ("moderate disability"-19.4\%-2015 and $20.1 \%-2016$ versus "severe disability" $-6.8 \%-2015$ and $6 \%$ in 2016) [5].

During the following years, Romania registered the same trend, so that both the persons in the new cases group and those in the revised cases group (every 1 - 3 years), classified as "moderate disability" were significantly more than those with "severe disability".

As regards disability evaluation, the medical report must contain the following:

1) Detailed medical history of persons to be assessed.

2) Patient tests and examinations results.

3) The consultant physician's opinion regarding the severity of the illnesses that lead to disability [4]. 
Table 1. A comparison between the EU and Romania, concerning the degree of disability [2] [5].

\begin{tabular}{|c|c|c|}
\hline & European union & Romania \\
\hline $\begin{array}{c}\text { Definition of } \\
\text { Disability }\end{array}$ & $\begin{array}{l}\text { Limitation in people's } \\
\text { activity due to health } \\
\text { conditions for at least } \\
\text { the past } 6 \text { months }\end{array}$ & $\begin{array}{l}\text { "Those people who associated disabilities which partially } \\
\text { or totally hinder the equal opportunity of access to the } \\
\text { community life and therefore need protection measure } \\
\text { for their social integration and inclusion" (art. } 2 \text {, } \\
\text { paragraphs } 1 \text { and } 2 \text {. Law no. 448/2006, modified, } \\
\text { revised and republished in 2008) }\end{array}$ \\
\hline $\begin{array}{l}\text { Degree of } \\
\text { Disability }\end{array}$ & $\begin{aligned} & \text { 1) Strongly limited } \\
= & \text { severe disability } \\
& \text { 2) Limited } \\
= & \text { moderate disability } \\
& \text { 3) Non-disabled }\end{aligned}$ & $\begin{array}{l}\text { 1) } 1^{\text {st }} \text { degree of disability (severe) corresponds to } \\
\text { incapacity for any work requiring constant attendance } \\
\text { 2) } 2^{\text {nd }} \text { degree of disability (accentuated) refers to an } \\
\text { incapacity for any work, but not requiring constant } \\
\text { attendance } \\
\text { 3) } 3^{\text {rd }} \text { degree of disability (moderate) implies the loss } \\
\text { of at least half of the working capacity, the disabled } \\
\text { persons still being able to perform a professional activity }\end{array}$ \\
\hline
\end{tabular}

Depending on the regulations from each EU Member States, the assessors may be:

- Social insurance physicians or multidisciplinary teams involving medical specialists

- Multidisciplinary teams involving non-medical specialists

- Social workers [4]

The social insurance physician plays a very important role. They decide if the claimant's illnesses fit into a disability degree or not and assess the functional capacity in the context of professional activity performance [4].

In Romania, social insurance physicians establish the severity of the clinical and functional diagnostic, as well as the degree of disability. In case of patients on compensation, depending on the illness severity, the same physicians determine whether it is necessary to assign a different disability degree, if the current degree should be maintained, they set the revision periods (between 1 and 3 years) or decide when the patients' health improvement allows for socio-professional reintegration. The claimants that are new cases to be subjected to assessment (people on medical leave, unemployed persons, persons employed based on an employment contract) can apply for disability compensation at County Houses of Public Pensions which are subordinated to the National House of Public Pensions and to the Ministry of Labor and Social Protection (Figure 3). The degree of disability is then assessed and certified by the social insurance physician from the same County House of Pensions.

Depending on the regulations from each EU states, assessors send completed patients' reports to upper decision levels, such as the Social Services Department or the Public Employment Service, so they can take the final decision, namely if the patient shall be paid a disability compensation or the patient shall return to work; these upper decision levels also establish the revision period [4]. 


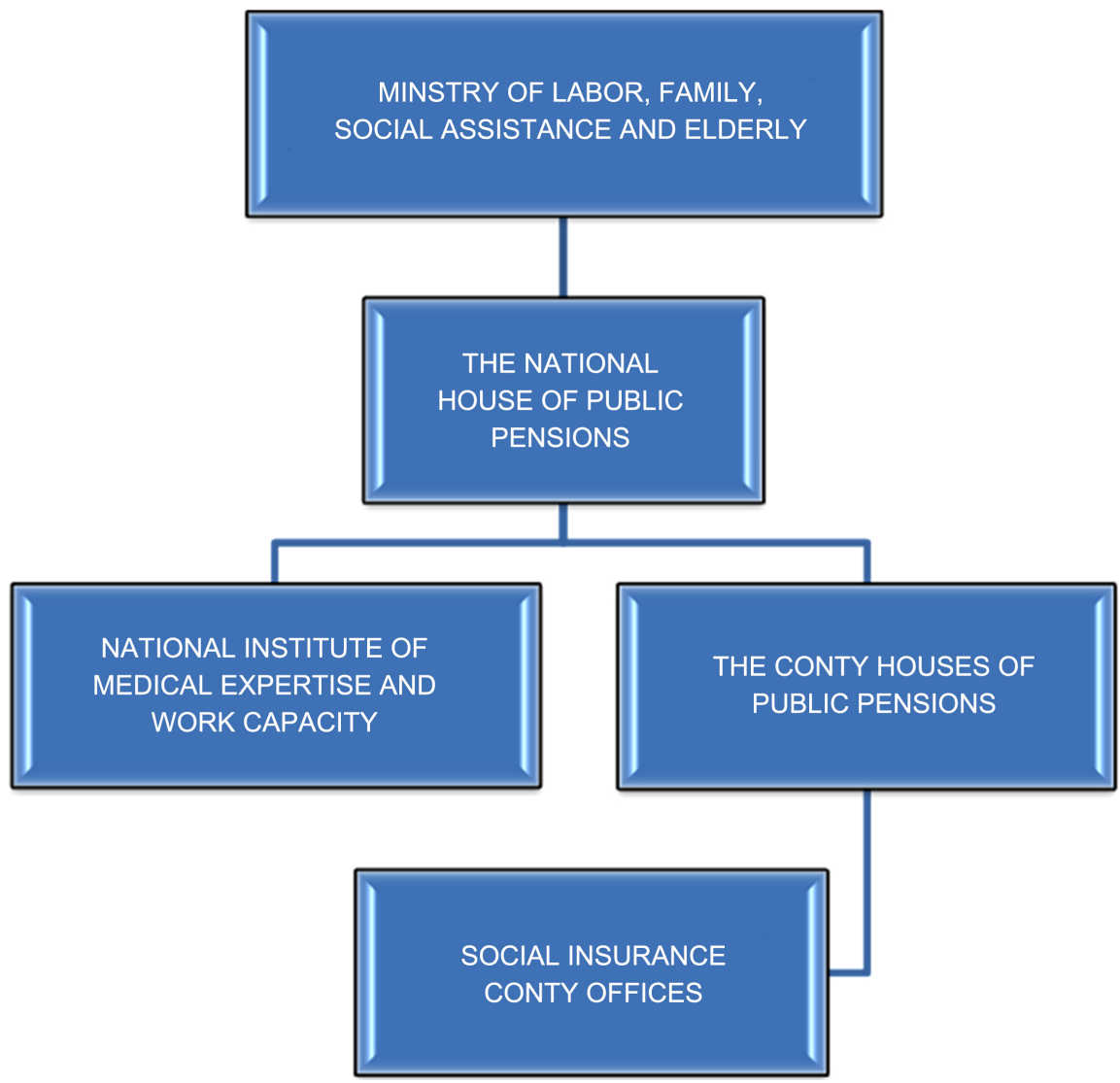

Figure 3. Schematic representation of the institutional circuit in Romania.

The outcomes of the study highlighted the following:

1) According to official data, in Romania the number of disabled people decreased gradually one year to another (in the last 5 years).

2) In the EU Member States, musculoskeletal disorders leading to disability were one of the most common compared to Romania where it ranked last.

3) From the point of view of the share in the total number of people with disabilities, according to the degree of disability, both in the EU Member States and in Romania, the number of moderate disabled people was double, respectively triple compared to the number of those with severe disability.

WHO elaborated a plan for 2014-2020 regarding the strategies concerning disabled persons:

1) Alleviation of impediments and improvement of access to health services and programs.

2) Improvement and extension of recovery, assistance and support services.

3) Development and research for a data collection system regarding international disability, in order to obtain viable results with favorable impact on social security services.

\section{Conclusions}

In conclusion, the term "disability" includes imbalances, limitations and re- 
strictions faced by patients in their daily life.

Each country applies its national criteria according to its legislation, when deciding the degree of disability.

The provisions of the current legislation in the area of the social insurance were presented from an objective perspective analyzing the weakness and the strong features as well, providing not only factual information, but also an analysis of specific aspects.

\section{Conflicts of Interest}

The authors declare no conflicts of interest regarding the publication of this paper.

\section{References}

[1] WHO (2015) WHO Global Disability Action Plan 2014-2021: Better Health for All People with Disability. https://apps.who.int/iris/handle/10665/199544

[2] Aurelian, A., Mihai, B., Adina, C., Ioana, A., Ana-Maria, A.L. and Gelu, O. (2016) Employment of People with Disabilities in Romania. International Archives of Medicine, 9.

[3] Hurjui, I. and Hurjui, C.M. (2018) General Considerations on People with Disabilities. Romanian Journal of Legal Medicine, 26, 225-228.

[4] Waddington, L. (2018) Disability Assessment in European States ANED 2017-2018 Synthesis Report. ANED 2017-2018.

[5] Grammenos, S. (2013) European Comparative Data in Europe 2020 and People with Disability. ANED 2018-2019. https://www.disability-europe.net/ 